\title{
Síndrome Oculoglandular de Parinaud Causada por Sporothrix schenckii
}

\author{
Lucas da Silva Madureira', Rafael Figueiredo Gatti ${ }^{1}$, Caroline Medeiros Prohmann', Jéssica Sanmiguel', Margarete Teresa Gottardo \\ de Almeida ${ }^{2}$, Fernanda Rodrigues de Oliveira Mattar ${ }^{3}$, João Roberto Antonio ${ }^{4}$ \\ 'Residente em Dermatologia, Faculdade Estadual de Medicina de São José do Rio Preto (FAMERP), São José do Rio Preto, Brasil \\ ${ }^{2}$ Bióloga, Professora de Microbiologia, Faculdade Estadual de Medicina de São José do Rio Preto (FAMERP), São José do Rio \\ Preto, Brasil \\ ${ }^{3}$ Dermatologista e Professora Adjunta do Programa de Residência Médica em Dermatologia da Faculdade Estadual de Medicina de \\ São José do Rio Preto (FAMERP), São José do Rio Preto, Brasil \\ ${ }^{4}$ Dermatologista, Chefe do Ambulatório de Dermatologia e Professor Emérito da Faculdade Estadual de Medicina de São José do \\ Rio Preto (FAMERP), São José do Rio Preto, Brasil
}

RESUMO - A síndrome oculoglandular de Parinaud consiste em forma especial de conjuntivite granulomatosa, muitas vezes relacionada à doença da arranhadura do gato, cuja apresentação clássica se caracteriza por uma síndrome febril acompanhada de granuloma conjuntival e linfonodomegalia ipsilateral. As doenças associadas a esta síndrome são doença da arranhadura do gato, infecção por herpes simples, esporotricose, blastomicose e coccidioidomicose, dentre outras. Relatamos o caso de uma paciente com quadro de enantema conjuntival unilateral à direita acompanhado do aparecimento de nódulos em pálpebra ipsilateral. Os exames complementares incluindo cultura confirmaram o diagnóstico de esporotricose. A paciente foi tratada com itraconazol com resolução do quadro.

PALAVRAS-CHAVE - Esporotricose; Sporothrix; Transtornos da Motilidade Ocular.

\section{Parinaud's Oculoglandular Syndrome Caused by Sporothrix schenckii}

ABSTRACT - Parinaud's oculoglandular syndrome consists of a special form of granulomatous conjunctivitis, often related to cat scratch disease, whose classic presentation is characterized by a fever, conjunctival granuloma and ipsilateral lymph node enlargement. Diseases associated with this syndrome are cat-scratch disease, herpes simplex infection, sporotrichosis, blastomycosis and coccidioidomycosis, among others. We report the case of a patient with a unilateral conjunctival enanthema on the right eye and nodules on the ipsilateral eyelid. Complementary examinations including culture confirmed the diagnosis of sporotrichosis. The patient was treated with itraconazole and got cured.

KEYWORDS - Ocular Motility Disorders; Sporothrix; Sporotrichosis.

\section{INTRODUÇÃO}

Esporotricose é uma infecção causada pelo fungo dimórfico Sporothrix schenckii, que apresenta distribuição global, porém é mais comum em regiões tropicais e subtropicais. ${ }^{1-3}$ As lesões características são nódulos cutâneos e subcutâneos que assumem uma disposição linear,
Correspondência: Lucas da Silva Madureira

Faculdade de Medicina de São José do Rio Preto, SP, Brasil.

Av. Brigadeiro Faria Lima, 5416

Vila São Pedro, São José do Rio Preto - SP, Brasil

CEP: 15090-000

E-mail: lucas.s.madureira@gmail.com

DOI: https://dx.doi.org/10.29021/spdv.76.4.886
Recebido/Received

17 Janeiro/January 2018

Aceite/Accepted

29 Maio/May 2018 


\section{Caso Clínico}

seguindo topografia da circulação linfática, que podem supurar e ulcerar. ${ }^{1,2} \mathrm{~A}$ disseminação visceral da doença é possível, sendo mais comum nos indivíduos imunossuprimidos. ${ }^{1,2}$

A transmissão da doença ocorre comumente devido a traumas durante manipulação de solo contaminado, gatos ou outros animais selvagens, ou pela inalação de esporos do fungo. ${ }^{1,2} \mathrm{O}$ acometimento ocular é possível, ocasionando, em alguns casos, a síndrome oculoglandular de Parinaud, ${ }^{4}$ caracterizada por forma especial de conjuntivite granulomatosa, muitas vezes relacionada à doença da arranhadura do gato, cuja apresentação clássica se caracteriza por uma síndrome febril acompanhada de granuloma conjuntival e linfonodomegalia ipsilateral. ${ }^{5}$ Esta síndrome pode ser ocasionada por diversos agentes infecciosos, estando sobretudo associada à doença da arranhadura do gato $^{6}$ (infecção por Bartonella henselae), mas também a outras infecções, como herpes simples, ${ }^{7}$ esporotricose, ${ }^{8}$ blastomicose ${ }^{9}$ coccidioidomicose ${ }^{10}$ e até mesmo infecções por Rickettsia. " Esta síndrome deve ser tratada o mais rápido possível a fim de evitar comprometimento da função visual do paciente. ${ }^{8}$

\section{CASO CLÍNICO}

Relatamos caso de paciente do sexo feminino de 72 anos procedente da cidade de São José do Rio Preto que compareceu ao ambulatório de dermatologia referindo quadro de olho vermelho unilateral à direita há 30 dias. Relatou que já havia realizado tratamento com colírios lubrificantes e antibióticos (tobramicina) sem melhora. Devido a surgimento de nodulações indolores em região palpebral inferior e pré-auricular direitas, foi-lhe prescrito doxiciclina $100 \mathrm{mg}$ de $12 \mathrm{em} 12$ horas por 14 dias sem benefício e foi encaminhada ao serviço de dermatologia do Hospital de Base de São José do Rio Preto.

A paciente referia labirintite, hipertensão arterial e depressão, em uso de losartan e sertralina, além de cinarizina apenas em momentos de crises de tontura. Relatava cirurgia para catarata no olho contralateral (esquerdo) aproximadamente 2 meses antes do início do quadro clínico e não recordava acidente ou traumatismo prévio no olho direito. Possuía um gato adulto como animal de estimação (aproximadamente 4 anos de idade), que, 2 meses antes do início do quadro clínico, havia falecido com lesão ulcerada em região cefálica. Além disso, cultivava plantas em seu domicílio, com manipulação diária de terra e adubo.

Na primeira consulta observava-se enantema conjuntival à direita, com pápulas normocrômicas e algumas eritematosas localizadas às pálpebras superior e inferior direitas, que variavam de 2 a $5 \mathrm{~mm}$ de diâmetro e confluíam formando uma placa violácea de superfície bosselada e consistência borrachóide na pálpebra inferior. Coexistia nódulo pré-auricular direito indolor com cerca de $0,8 \mathrm{~cm}$ consistência fibroelástica, recoberto por pele de coloração violácea, com centro exulcerado, que a paciente

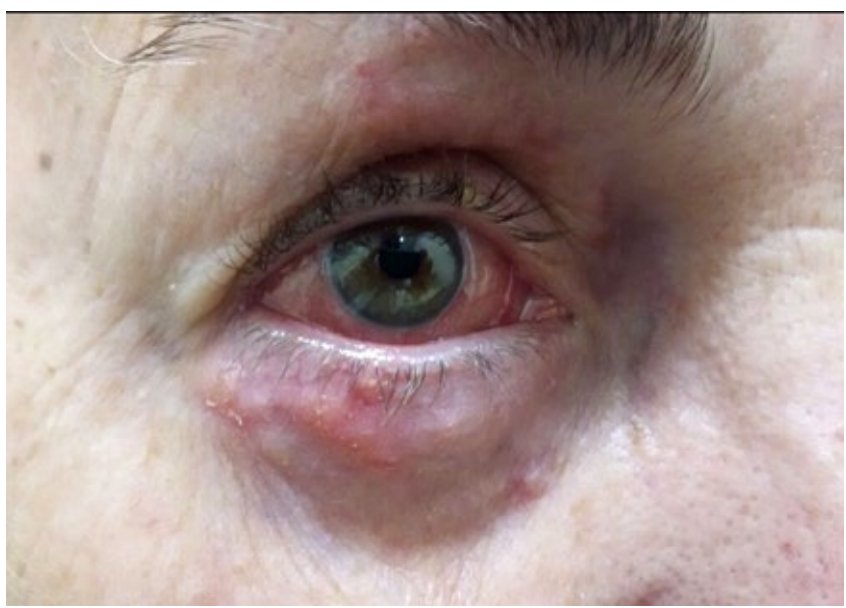

Figura 1 - Observação inicial com destaque para o enantema conjuntival e para os pápulas e nódulos na pálpebra inferior direita.

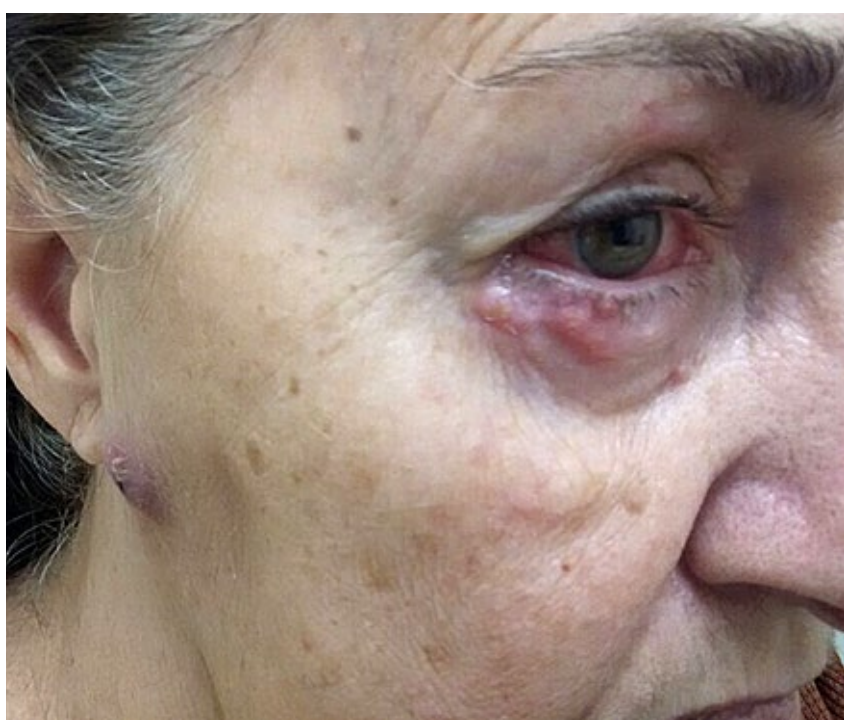

Figura 2 - Observação inicial, com o enantema conjuntival, pápulo-nódulos palpebrais confluentes na pálpebras inferior e linfonodo pré-auricular recoberto por crosta.

relatou ter apresentado drenagem de secreção de aspecto purulento inicialmente. Palpava-se ainda linfonodo indolor com 1,0 cm em cadeia submandibular direita, com consistência fibroelástica e não aderido a planos profundos (Fig.s 1, 2 e 3 ).

Exames laboratoriais incluindo hemograma e avaliação de função hepática e renal, sorologias para hepatites virais e VIH foram normais ou negativos. A biópsia de pápula da pálpebra inferior direita mostrou neovascularização e infiltrado predominantemente linfoplasmocitário em derme média e profunda, sem reação granulomatosa ou presença de microorganismos (Fig. 4). No entanto, a cultura do fragmento de biópsia cutânea em que meio ágar Sabouraud foi positiva para o fungo Sporothrix 


\section{Caso Clínico}

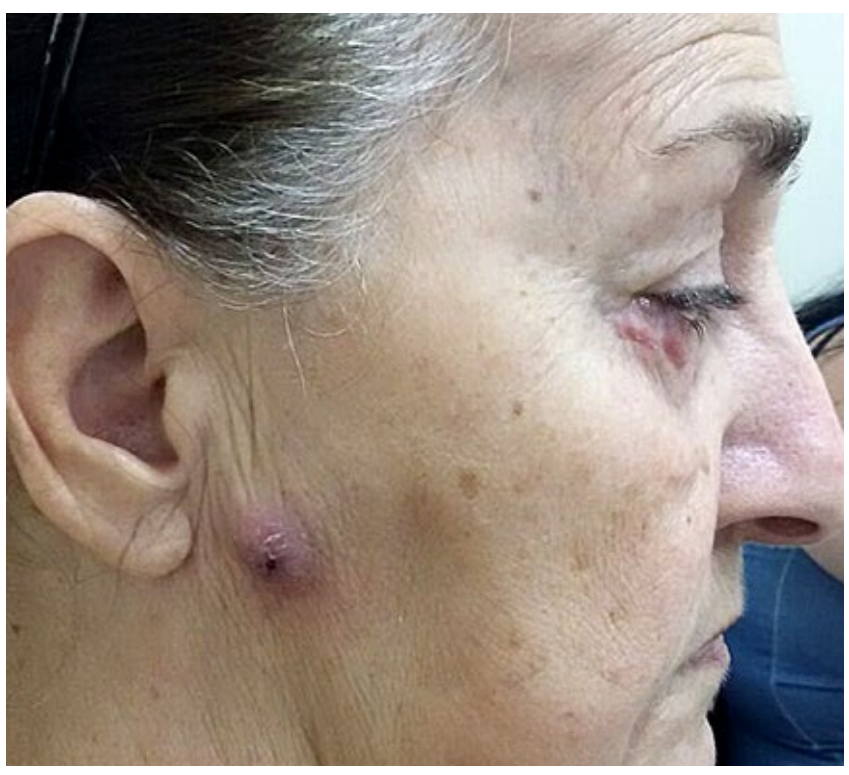

Figura 3 - Observação inicial com destaque para o linfonodo pré-auricular com pequeno ponto central de drenagem de secreção.

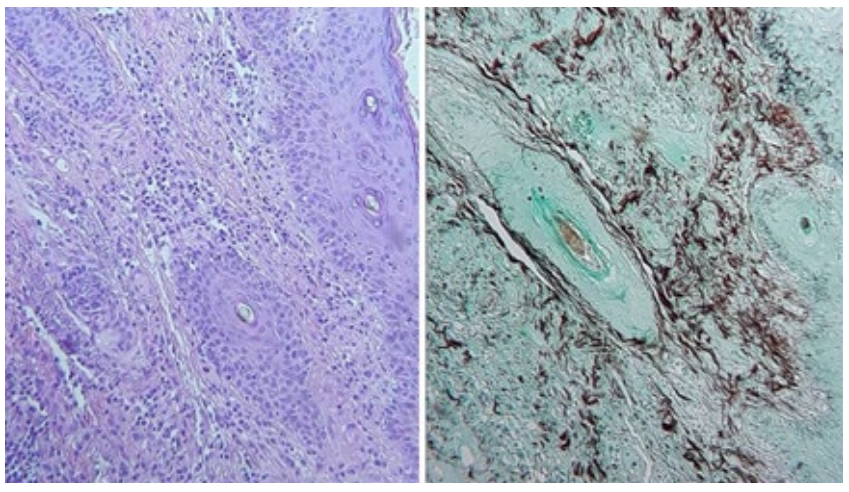

Figura 4 - Estudo histopatológico, mostrando à esquerda infiltrado linfoplasmocitário na derme profunda, com menor quantidade de neutrófilos e ausência de reação granulomatosa (H\&E) sem evidencia de estruturas fúngicas na coloração pela prata (direita).

schenckii e o microcultivo também apresentou alterações sugestivas deste fungo (hifas hialinas finas com esporos dispostos em arranjo semelhante à flor "margarida"), fechando assim o diagnóstico de esporotricose cursando com síndrome oculoglandular de Parinaud (Fig.s 5 e 6). A cultura para bactérias foi negativa.

A paciente foi tratada com itraconazol $200 \mathrm{mg}$ via oral de 12 em 12 horas por 24 semanas, evoluindo com resolução do quadro clínico (Fig.s 7 e 8). A paciente evoluiu com melhora do quadro de olho vermelho e diminuição da dimensão do nódulo pré-auricular a direita. Não apresentou sequelas oculares após o tratamento, porém optou-se por manter seguimento dermatológico e oftalmológico da paciente, a despeito do tratamento concluído.

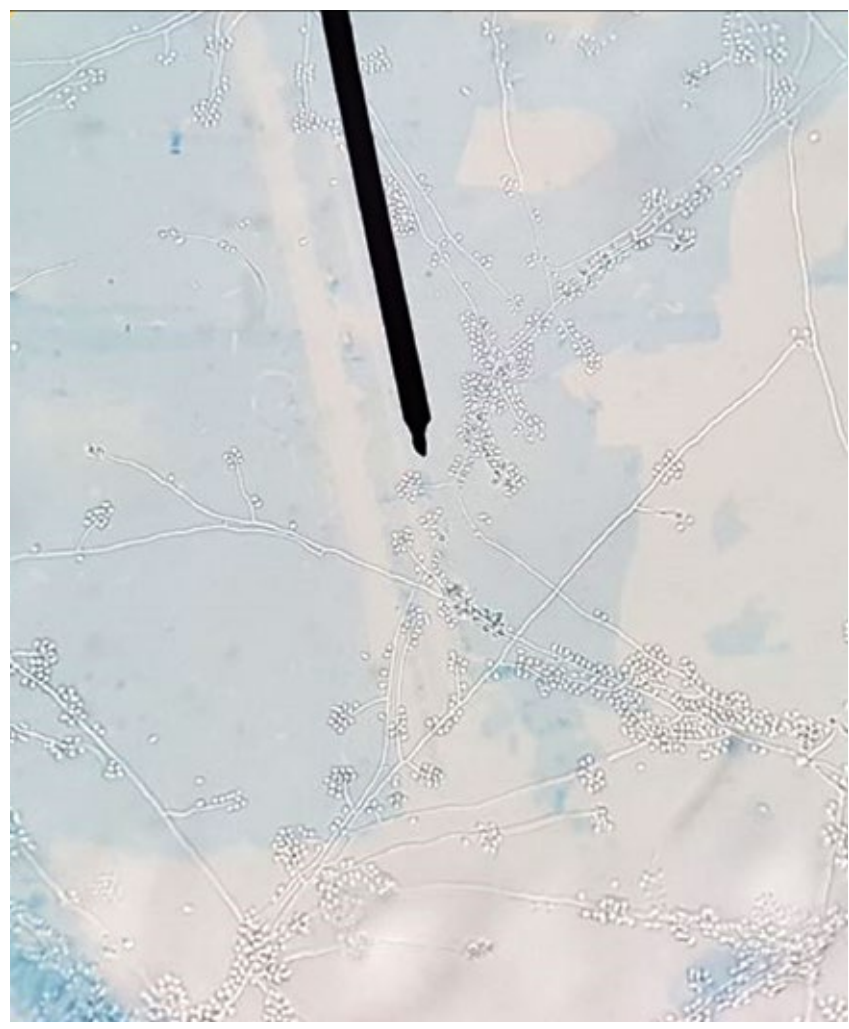

Figura 5 - Microcultivo de Sporothrix schenkii, mostrando hifas hialinas finas com esporos dispostos em arranjo semelhante à flor "margarida".

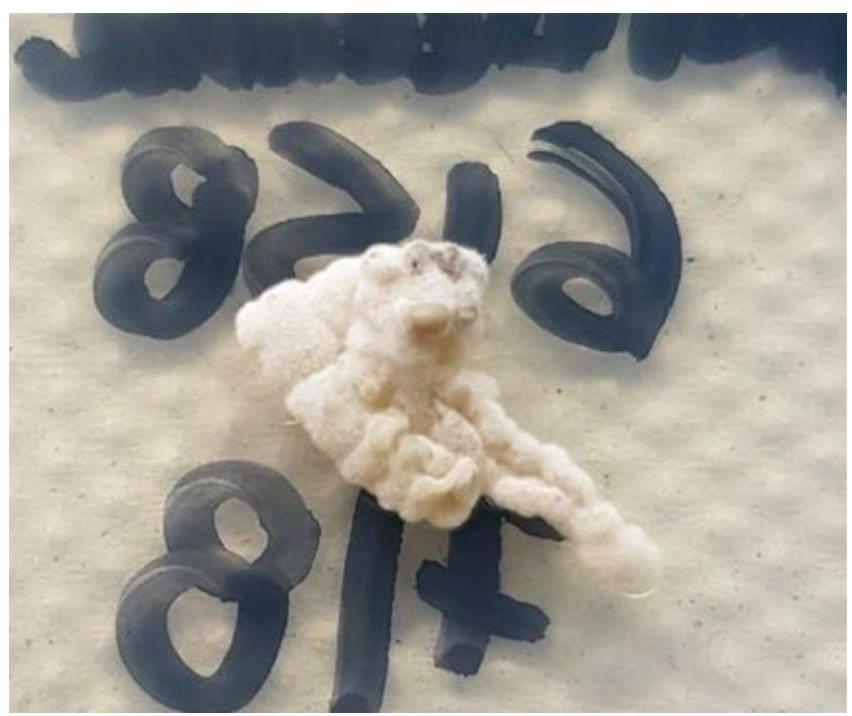

Figura 6 - Aspecto da cultura típica de Sporothrix schenkii, obtida após cultura de fragmento de biópsia palpebral.

\section{DISCUSSÃO}

Por ser uma condição rara, a síndrome de Parinaud não é encontrada rotineiramente no consultório do médico 


\section{Caso Clínico}

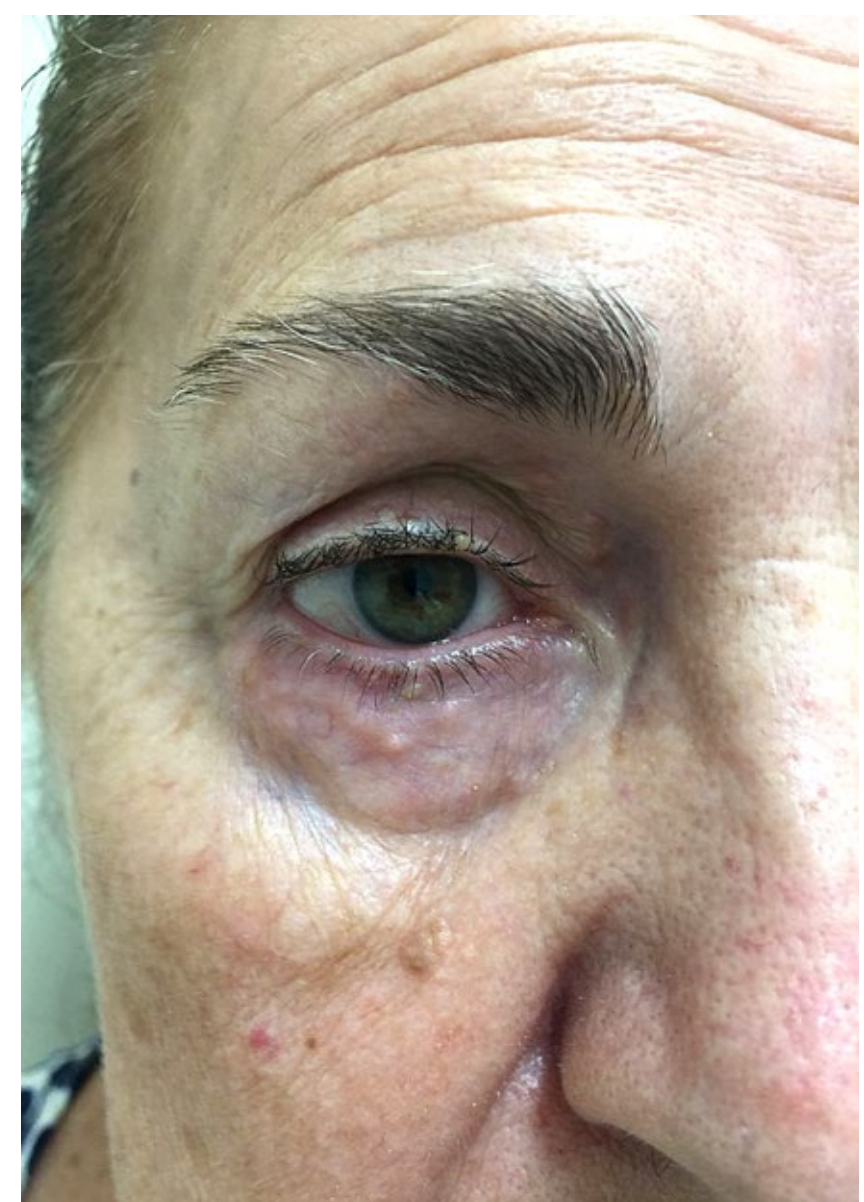

Figura 7 - Melhoria do enantema conjuntival e dos nódulos palpebrais após 16 semanas de tratamento com itraconazol $400 \mathrm{mg} / \mathrm{d}$.

dermatologista. No entanto, devido ao potencial de ocasionar perda da função visual se não tratada adequadamente, é importante reforçar a importância do diagnóstico certeiro e precoce desta doença. Embora esteja mais comumente relacionada à doença da arranhadura do gato, outros microorganismos podem também ocasionar a síndrome, dentre eles vírus, micobactérias típicas e atípicas, espiroquetas e fungos.

A anamnese completa é fundamental na elucidação diagnóstica, dado que a história de contato profissional ou doméstico com animais ou materiais contaminados é rotineiramente encontrada e leva à suspeita diagnóstica. No caso descrito, o contato com gatos, terra e plantas foi crucial para a suspeita clínica. Já a cultura para fungos a partir do fragmento de biópsia foi o exame fundamental para a elucidação do agente etiológico relacionado ao quadro desta paciente, visto que tanto a esporotricose quanto a bartonelose possuem características epidemiológicas e clínicas em comum. Em relação ao estudo histopatológico, a esporotricose e a bartonelose também podem apresentar características em comum: granulomas constituídos por histiócitos, infiltrado com plasmócitos e microabscessos de

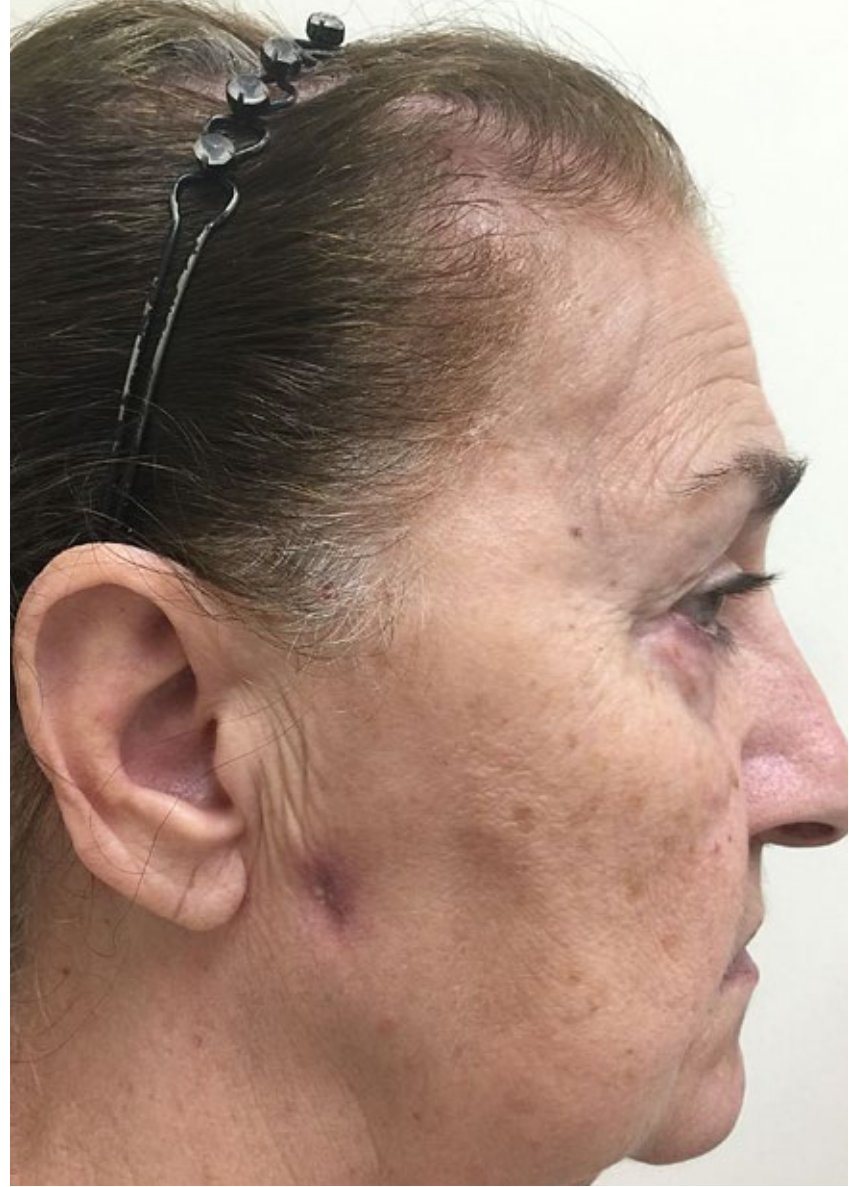

Figura 8 - Resolução do linfonodo pré-auricular direito após 16 semanas de tratamento com itraconazol $400 \mathrm{mg} / \mathrm{d}$.

neutrófilos. ${ }^{12,13}$ Raramente os fungos causadores da esporotricose são encontrados na histologia, mesmo com uso de colorações especiais. ${ }^{12}$

Para casos relacionados à Bartonella sp., imunofluorescência indireta pode ser utilizada, ${ }^{14}$ mas a técnica de PCR em tempo real apresenta maior especificidade e é especialmente útil em pacientes com endocardite por este microorganismo, ${ }^{15}$ pois estes pacientes dispõem apenas de amostras de soro para diagnóstico. No caso da esporotricose, o melhor método para diagnóstico é a detecção do agente etiológico em meio de cultura adequado. ${ }^{3}$ Reação em cadeia de polimerase (PCR) também pode ser utilizada, porém está menos disponível. O tratamento com iodeto de potássio é possível para lesões cutâneas e possui baixo custo, ${ }^{2}$ porém o itraconazol, utilizado no presente caso, ainda é considerado uma das drogas de escolha para o tratamento da doença, ${ }^{3}$ sendo recomendado a dose de 100 a 200 mg por dia e a duração de 3 a 6 meses. ${ }^{12}$ 
Conflitos de interesse: Os autores declaram não possuir conflitos de interesse.

Suporte financeiro: $O$ presente trabalho não foi suportado por nenhum subsídio ou bolsa.

Confidencialidade dos dados: Os autores declaram ter seguido os protocolos do seu centro de trabalho acerca da publicação dos dados de doentes.

Direito a privacidade e consentimento escrito: Os autores declaram que pediram consentimento ao representante legal para usar as imagens no artigo.

Protecção de pessoas e animais: Os autores declaram que os procedimentos seguidos estavam de acordo com os regulamentos estabelecidos pelos responsáveis da Comissão de lnvestigação Clínica e Ética e de acordo com a Declaração de Helsínquia da Associação Médica Mundial.

Consentimento do doente: Obtido.

Conflicts of interest: The authors have no conflicts of interest to declare.

Financing Support: This work has not received any contribution, grant or scholarship.

Confidentiality of data: The authors declare that they have followed the protocols of their work center on the publication of data from patients.

Privacy policy and informed consent: The authors declare that the legal representative of the patient gave written informed consente for the use of patient's fotos in this article.

Protection of persons and animals: The authors declare that the procedures followed were in accordance with the regulations of the relevant clinical research ethics committee and with those of the Code of Ethics of the World Medical Association (Declaration of Helsinki).

Patient consent: Obtained.

\section{REFERÊNCIAS}

1. Ramos-e-Silva M, Vasconcelos C, Carneiro S, Cestari T. Sporotrichosis. Clin Dermatol. 2007; 25:181-7.

2. Morris-Jones R. Sporotrichosis. Clin Exp Dermatol. 2002; 27:427-31.

3. Lopes-Bezerra LM, Schubach AO, Costa RO. Sporothrix schenckii and sporotrichosis. An Acad Bras Cienc. 2006;78:293-308.

4. Ribeiro AS, Bisol T, Menezes MS. Síndrome oculoglandular de Parinaud causada por esporotricose. Rev Bras Oftalmol. 2010;69):317-22.

5. Ouvrier R. Henri Parinaud and his syndrome. Med J Aust. 1993; 158:711-4.

6. Huang MC, Dreyer E. Parinaud's oculoglandular conjunctivitis and cat-scratch disease. Int Ophthalmol Clin. 1996; 36:29-36.

7. Caputo GM, Byck H. Concomitant oculoglandular and ulceroglandular fever due to herpes simplex type I. Am J Med. 1992; 93:577-80.

8. Ferreira CP, Nery JA da Costa, de Almeida AC, Ferreira LC, Corte-Real S, Conceição-Silva F. Parinaud's oculoglandular syndrome associated with Sporothrix schenckii. IDCases. 2014; 1:38-9.

9. Bartley GB. Blastomycosis of the eyelid. Ophthalmology. 1995; 102:2020-3.

10. Wood TR. Ocular coccidioidomycosis. Report of a case presenting as Parinaud's oculoglandular syndrome. Am J Ophthalmol. 1967; 64:587-90.

11. Abroug N, Khairallah-Ksiaa I, Kahloun R, Khochtali S, Zaouali S, Khairallah M. Parinaud's oculoglandular syndrome revealing subclinical Rickettsia conorii infection. Int Ophthalmol.2015; 35:717-9. doi: 10.1007/s10792-015-0094-2.

12. Campbell I, Pacheco TM. Compêndio de Micologia Médica. 2 ed. Rio de Janeiro: Editora Guanabara Koogan; 2010.

13. Angelakis E, Edouard S, La Scola B, Raoult D. Bartonella henselae in skin biopsy specimens of patients with cat-scratch disease. Emerg Infect Dis. 2010; 16:1963-5. doi: 10.3201/eid1612.100647.

14. Hernández-Porto M, Sánchez Burgos R, Martínez de Las Heras B, Rodriguez Luis JC. Palpebral conjunctivitis and preauricular adenopathy: Parinaud's oculoglandular syndrome. Enferm Infecc Microbiol Clin. 2017; 35:122-4. doi: 10.1016/i.eimc.2015.04.012.

15. Blanco J, Jado JR, Marín I, Sanfeliu M, Portillo I, Anda $A$, et al. Microbiological diagnosis of emerging bacterial pathogens: Anaplasma, Bartonella, Rickettsia, and Tropheryma whipplei. Enferm Infecc Microbiol Clin. 2008; 26: 573-80. 